\title{
Article \\ Compass Cue Integration and Its Relation to the Visual Ecology of Three Tribes of Ball-Rolling Dung Beetles
}

\author{
Lana Khaldy $^{1, *}$, Claudia Tocco ${ }^{1,2}$, Marcus Byrne ${ }^{2}$ and Marie Dacke ${ }^{1,2}$ \\ 1 Lund Vision Group, Department of Biology, Lund University, Sölvegatan 35, 22362 Lund, Sweden; \\ claudia.tocco@biol.lu.se (C.T.); marie.dacke@biol.lu.se (M.D.) \\ 2 School of Animal, Plant and Environmental Sciences, University of the Witswatersrand, 1 Jan Smuts Avenue, \\ Braamfontein, Johannesburg 2000, South Africa; marcus.byrne@wits.ac.za \\ * Correspondence: lana.khaldy@biol.lu.se
}

check for

updates

Citation: Khaldy, L.; Tocco, C.; Byrne, M.; Dacke, M. Compass Cue Integration and Its Relation to the Visual Ecology of Three Tribes of Ball-Rolling Dung Beetles. Insects 2021, 12, 526. https://doi.org/ $10.3390 /$ insects 12060526

Academic Editors: Sylvia Anton and Romina B. Barrozo

Received: 9 May 2021

Accepted: 3 June 2021

Published: 6 June 2021

Publisher's Note: MDPI stays neutral with regard to jurisdictional claims in published maps and institutional affiliations.

Copyright: (C) 2021 by the authors. Licensee MDPI, Basel, Switzerland. This article is an open access article distributed under the terms and conditions of the Creative Commons Attribution (CC BY) license (https:// creativecommons.org/licenses/by/ $4.0 /)$.
Simple Summary: To escape competition for food at the dung pat, ball-rolling dung beetles shape a piece of dung into a sphere and roll it away. To maintain their bearing, these beetles integrate directional information from a range of celestial cues. For the majority of diurnal dung beetles living in open habitats, the most dominant of these cues is the sun. It has recently been demonstrated that beetles living in closed habitats, with closely spaced trees and tall grass, rely predominantly on directional information provided by polarised skylight rather than the sun. Taken together, these findings suggests that the orientation strategy of the beetle is influenced by the animal's visual ecology. To further investigate the relative weighting of cues in the orientation system of beetles, and its relation to their visual ecology, we investigated the orientation strategy of ball-rollers from three different dung beetle tribes, all present within the same savanna biome. We find that species within a tribe share the same orientation strategy, but that this strategy differs across tribes. We conclude that, despite dramatic intertribal differences in body size and external eye design, the dynamic heading direction network of the South African ball-rolling dung beetles is well adapted to guide the foraging insect in the habitat that it normally traverses.

Abstract: To guide their characteristic straight-line orientation away from the dung pile, ball-rolling dung beetles steer according to directional information provided by celestial cues, which, among the most relevant are the sun and polarised skylight. Most studies regarding the use of celestial cues and their influence on the orientation system of the diurnal ball-rolling beetle have been performed on beetles of the tribe Scarabaeini living in open habitats. These beetles steer primarily according to the directional information provided by the sun. In contrast, Sisyphus fasciculatus, a species from a different dung-beetle tribe (the Sisyphini) that lives in habitats with closely spaced trees and tall grass, relies predominantly on directional information from the celestial pattern of polarised light. To investigate the influence of visual ecology on the relative weight of these cues, we studied the orientation strategy of three different tribes of dung beetles (Scarabaeini, Sisyphini and Gymnopleurini) living within the same biome, but in different habitat types. We found that species within a tribe share the same orientation strategy, but that this strategy differs across the tribes; Scarabaeini, living in open habitats, attribute the greatest relative weight to the directional information from the sun; Sisyphini, living in closed habitats, mainly relies on directional information from polarised skylight; and Gymnopleurini, also living in open habitats, appear to weight both cues equally. We conclude that, despite exhibiting different body size, eye size and morphology, dung beetles nevertheless manage to solve the challenge of straight-line orientation by weighting visual cues that are particular to the habitat in which they are found. This system is however dynamic, allowing them to operate equally well even in the absence of the cue given the greatest relative weight by the particular species.

Keywords: orientation; orientation strategy; visual ecology; dung beetle; compass cues 


\section{Introduction}

To successfully navigate the world, animals often rely on directional information from more than one sensory channel [1-3]; fruit flies require visual feedback to localize an odour source [4], bees are better at pin-pointing their nest entrance with the addition of olfactory cues [5] and Bogong moths use the Earth's magnetic field in combination with landmarks to localize Alpine caves [6]. In addition, orienting insects seem to afford the greatest weight to the directional information that conveys the highest certainty at a given moment [7]. Monarch butterflies primarily rely on the sun to find their route across the North American continent [8] but will refer to polarised skylight for directional guidance as soon as this bright solar cue is obstructed [9-11], and as the sun climbs high in the sky, becoming less reliable for directional input, dung beetles and ants rely more heavily on directional information provided by wind [1,12]. Homing ants, which find their way back to their nest by path integration and landmarks, also employ a dynamic strategy for reliable navigation; as these foragers are displaced further and further from their nest and the visual scenery around them becomes increasingly unfamiliar, they shift the relative directional weight of their path integrator and landmark guidance in favour of the former to lead them back home [13].

Not surprisingly, the visual ecology of an animal influences what directional cues to follow where and when. Rodent and fish species living in spatially complex environments will rely more on egocentric cues to find their way compared to species inhabiting more open habitats [14-16]. Another example can be found among ants, where species inhabiting cluttered, landmark-rich spaces, rely more on landmark guidance compared to desert ants that forage in open, featureless habitats [13,17-20]. While these differences in directional guidance appear to be species specific, and strictly tuned to the visual environment in which the animal lives, a dynamic influence of the visual ecology of the navigator can be observed in the strictly nocturnal, savanna-living dung beetle, Scarabaeus satyrus (Fabricius). During a moon-lit night, this beetle orients using polarised lunar skylight in preference to the moon, but if coerced to roll during the day, the heading direction network of the beetle shifts the relative weight of these two types of celestial cues in favour of directional information provided by the sun [21].

Diurnal ball-rolling dung beetles steer their characteristic straight-line escapes from a dung pile [22-27] by directional information provided by the sun [21,23,24,27], the polarised skylight [26,28], the gradients of intensity [28] and colour that form across the daytime sky [29], as well as the prevailing winds [1]. Our understanding of how these insects roll straight over the sun-lit savanna is largely based on behavioural, morphological and neurobiological studies of beetles from the tribe Scarabaeini $[1,21,23,27,28,30]$ (but see $[24,26,31]$ and below). In these studies, we repeatedly found that if the directional information from the sun is set in conflict with other celestial cues, the beetles change their bearings according to the position of the sun $[23,30]$. These experiments clearly demonstrate that directional information from the sun is given the greatest relative weight during straight-line orientation in these large and iconic dung beetle species. In addition, it seems that, contrary to homing ants, which choose an intermediate route when directional cues are set in conflict [12,32-36], dung beetles do not average the dictates of the directional sources, but instead predominantly rely on the directional information given the greatest weight at that time. Consequently, only when the sun is hidden from view will the Scarabaeini beetles turn in response to the rotation of an overhead pattern of polarised light [28].

It was recently shown that a savanna woodland-living species of the tribe Sisyphini, Sisyphus fasciculatus, displays a different behaviour; when rolling under a polarising filter under a sun-lit sky outdoors, this beetle changes its bearing in accordance with the turn of the polariser [26]. This suggests that these small beetles, which traverse litter strewn terrain under closely spaced trees or through tall grass, predominantly rely on directional information from the celestial pattern of polarised light [26]. Due to this contrasting behaviour, Khaldy et al. [26] suggested that the visual ecology of the orientation system of the different species of dung beetle, just as in ants, is influenced by their distinct habitat associations. Here, we continue to explore the relative weight of directional information in 
the heading direction network of three species of dung beetles from three different tribes, foraging in the closed or open habitat of the same savanna biome.

\section{Materials and Methods}

\subsection{Selection of Dung Beetle Species}

The three species of ball-rolling dung beetles initially included in this study all occur in the savanna biome [37]: Kheper nigroaeneus [tribe Scarabaeini], Garreta unicolor (tribe Gymnopleurini) and Sisyphus fasciculatus (tribe Sisyphini). The addition of G. nitens (tribe Gymnopleurini) as a fourth test species from the same biome was inspired by the unexpected finding that the heading direction network of G. unicolor did not attribute the greater directional weight to either the sun or the polarised light pattern (see Section 3.6). The experiments performed with this species is thus limited to defining the relative weight of directional cues in its orientation system.

\subsection{Collection and Maintenance of Animals}

Beetles were collected using dung-baited pit-fall traps in the Wits University, Pullen nature reserve (closed and open habitat) $\left(31.10^{\circ} \mathrm{E}, 25.34^{\circ} \mathrm{S}\right)$ (Kheper nigroaeneus, Garreta unicolor, Sisyphus fasciculatus) and Bersig Eco Estate (open habitat) $\left(27.95^{\circ} \mathrm{E}, 24.78^{\circ} \mathrm{S}\right)$ (Garreta nitens), South Africa. For illustrative purposes, the sampled habitats were photographed from the air (DJI Mavic 2) and from the ground (Nikon D810 fitted with an $8 \mathrm{~mm}$ fisheye lens) (see Figure 1). Once collected, beetles were maintained outside, in soil-filled, transparent plastic bins, and fed with fresh cow dung every second day. Beetles taken to the Department of Biology, Lund University, Sweden, were housed in large plastic bins $(50 \times 36 \times 27 \mathrm{~cm})$ in a light- and temperature-controlled room, under a $12 \mathrm{~h}$ light/dark cycle at a room temperature of $26^{\circ} \mathrm{C}$.
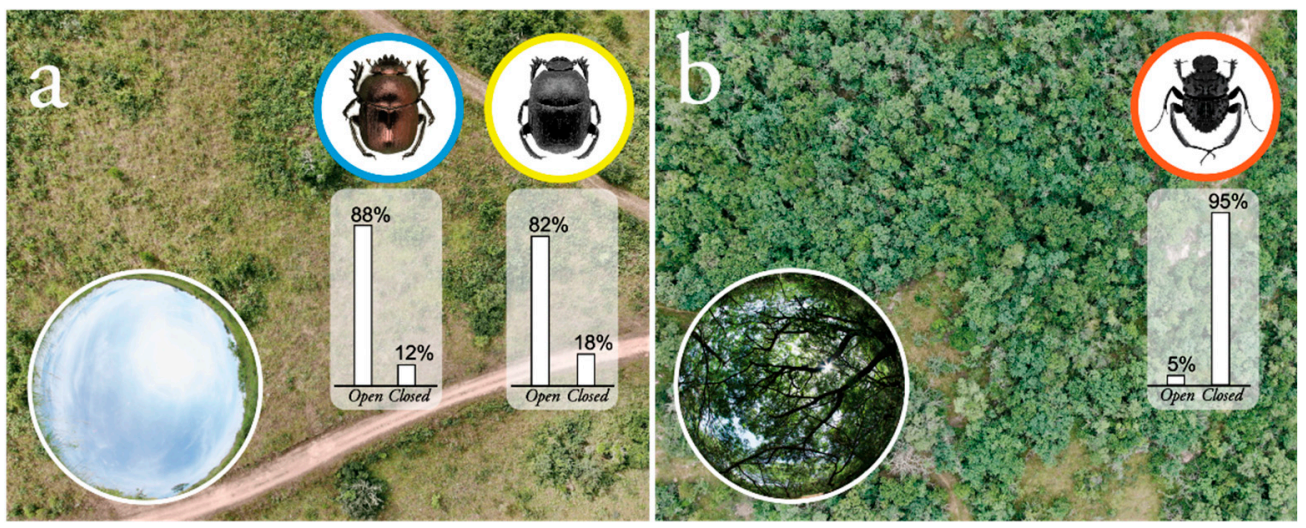

Figure 1. Dung beetles from three tribes of ball-rollers and the bioregions they inhabit. Beetles from three tribes of ball-rollers (blue-bordered image: Scarabaeini; yellow-bordered image: Gymnopleurini; red-bordered image: Sisyphini) were collected within the same savanna biome. K. nigroaeneus and G. unicolor were predominantly found actively foraging in the open habitat (a) and S. fasciculatus predominantly foraged within the closed habitat $(\mathbf{b})$ of the same bioregion. A histogram, illustrating the percentage of individuals found in the open and closed habitat over three consecutive sampling days, is presented below each respective beetle image. A $180^{\circ}$ view of the sky from the ground perspective of the beetle is included at the bottom of each panel.

\subsection{Determining Habitat Preference and Eye Size of the Dung Beetles \\ 2.3.1. Habitat Preference}

To determine the habitat preferences of Kheper nigroaeneus, Garreta unicolor and Sisyphus fasciculatus, pitfall-traps were placed in the open habitat (dominant grass species: Heteropogon contortus, Sporobolus pyramidalis and Chloris pycnothrix) (Figure 1a) and closed habitat (dominant tree species: Sclerocarya birrea, Searsia pentheri and Erythrina lystemon) (Figure 1b) for three non-consecutive sampling sessions during March 2019. Traps were 
emptied and re-baited with fresh dung every $3 \mathrm{~h}$ during daylight hours. For more details regarding the trapping method, see Khaldy et al., 2020 [26]. The habitat preference for G. nitens, that shares the same savanna biome, was not defined.

\subsubsection{Statistical Analysis of Habitat Preference}

To test for differences in species abundance between habitat types, generalized linear mixed models (GLMMs) [38] in R (R Core Team 2020, Vienna, Austria, https:/ / www.Rproject.org/, accessed on 31 May 2021), used with lme4 [39], were fitted. Each trap of each sampling event was used as a sampling unit, with a total of 155 sampling units. The ShapiroWilk test was used to test for normality in the residual distribution of the species abundance. The abundance of each species was non-normal count data and Poisson error distribution was specified in each model [39]. In all GLMMs, habitat type was treated as a fixed factor and sampling day as a random factor to block the layout of the sampling design.

\subsubsection{Eye Size}

To measure the eye surface area, the right eye of ten individuals of each species was covered with a thin layer of transparent nail polish. Once dried, the coat of nail polish was peeled off from the eye, cut and mounted flat on a microscope slide. The images of the flattened impression of the eyes were taken with a stereo microscope (Zeiss Stereo Discovery V12) and the absolute area was measured using ImageJ (Rasband, W.S., ImageJ, U. S. National Institutes of Health, MD, USA, https://imagej.nih.gov/ij/, 1997-2018, accessed on 20 May 2021). As K. nigroaeneus possesses a complete canthus, the absolute eye area for this species was calculated as the sum of the dorsal and ventral eye area.

\subsection{Behavioural Experiments}

Outdoors, experiments were performed under clear skies, at solar elevations between $45^{\circ}$ and $60^{\circ}$, at Bersig Eco Estate and Pullen nature reserve between March 2018 and November 2019. In Lund University, Sweden, the beetles were presented with a green unpolarised light spot (Adafruit DotStar Digital LED Strip; emission peak $530 \mathrm{~nm}$, Adafruit Industries, New York, NY, USA), a previously documented replacement for the sun in the heading direction network of the beetle [21], at an elevation of $45^{\circ}$, in an otherwise completely darkened indoor room. An overhead Sony Handycam HDR-CX730E (fitted with a $0.42 \times$ wide angle lens), mounted from above with the lens facing downwards, was used to record exit bearings.

\subsubsection{Orientation Performance of Dung Beetles}

To determine the beetle's orientation performance under an open sky, each individual was repeatedly placed beside its ball in the centre of a circular, flat, sand-coated arena, where the effective radius was set to a distance equivalent to the length of 20 steps for the species tested (K. nigroaeneus; $59 \mathrm{~cm}$, G. unicolor; $32 \mathrm{~cm}$, S. fasciculatus; $32 \mathrm{~cm}$ ) (for detailed data see Supplementary Table S1). Each beetle was allowed to roll its ball to the arena perimeter ten times. Ten individuals per species were tested.

\subsubsection{Relative Weighting of Directional Cues in the Orientation System of Dung Beetles}

For each experimental treatment, the beetle was placed alongside its dung ball, in the centre of a $50 \mathrm{~cm}$ radius circular arena and allowed to roll its ball to the perimeter where its exit bearing was noted. For conditions requiring a polarising filter, a circular $30 \mathrm{~cm}$ radius, UV/Visible light-transparent polarisation filter (BVO UV Polarizer, Bolder Vision Optik@, Boulder, CO, USA) was positioned over the centre of the arena. The filter was mounted on four legs $(10 \mathrm{~cm}$ in height) and fitted with a black cloth curtain around its perimeter to prevent the entry of light from outside the filter. The exit bearing was recorded when the beetle reached the filter perimeter. Upon completion of the beetle's first roll, the position of the test cue(s) was rotated by either $90^{\circ}$ or $180^{\circ}$ (see Section 2.4.3. below). The beetle was allowed to exit the arena and its second exit bearing was noted. A third exit, presenting the 
same visual parameters as in the first trial, was performed as a control to test whether the beetle could follow approximately the same bearing throughout the experiment. Angular change was calculated as the difference in bearing between the first and second exit (test), or first and third exit (control). In total, each individual rolled from the centre to the edge of the arena (or filter perimeter) three times. In all outdoor experiments, 20 individuals per species were tested. For the indoor experiments, 10 individuals were tested for each species.

\subsubsection{Manipulation of Directional Input}

Sun (ersatz or real): In the field, the sun's apparent position was changed by $180^{\circ}$ using a mirror $(30 \times 30 \mathrm{~cm})$, while simultaneously concealing the real sun from the beetle's field of view using a wooden shade board $(100 \times 75 \mathrm{~cm})$. Indoors, the azimuth of the ersatz sun was changed by $180^{\circ}$ between trials by switching off and on the green light spot at different relative positions.

Polarised light: In the field, the UV/Visible light-transparent polarisation filter was turned by $90^{\circ}$, between consecutive rolls, either under a full view of the sun or with the sun shielded from the beetle's field of view by the shade board. The initial orientation of the filter was alternated for each beetle, with every second beetle starting with the polarisation filter aligned to the natural polarisation band of the sky, and every other beetle with the filter aligned perpendicular to the natural polarisation band of the sky.

Sun and polarised light: In these experiments, the polarising filter was turned by $90^{\circ}$ in combination with a $180^{\circ}$ change in the solar position, as described above.

\subsubsection{Circular Statistics}

Circular statistics on measured data was performed using Oriana 4.0 (Kovach Computing Services, Anglesey, UK). All circular data are reported as mean \pm one circular standard deviation. Distributions of exit angles were analysed using Rayleigh's uniformity test for circular data [40]. Changes in direction between treatments were calculated by measuring the angular difference in exit bearing between two exits from the arena and analysed using a v-test with an expected mean of $0^{\circ}$ for the control experiments and $180^{\circ}$ for the mirrored sun/ersatz sun experiments. To test for homogeneity of two or more samples, a Mardia-Watson-Wheeler test was used.

\section{Results}

\subsection{Habitat Preference}

Kheper nigroaeneus and G. unicolor were primarily found actively foraging within the open habitat (open vs. closed habitat: K. nigroaeneus; $p<0.001$, z-value $=8.60$, estimate = 2.09, $\mathrm{N}=165 ;$ G. unicolor $; p<0.001$, $\mathrm{z}$-value $=18.41$, estimate $=1.55, \mathrm{~N}=971$, GLMM test) (Figure 1a, histogram), while $S$. fasciculatus was mainly found in the closed habitat (closed vs. open habitat: $S$. fasciculatus; $p<0.001$, z-value $=-19.39$, estimate $=-2.87$, $\mathrm{N}=939$, GLMM test) of the same bioregion (Figure 1b, histogram). These findings strongly suggest that K. nigroaeneus and G. unicolor preferentially forage for dung in the open habitat, while $S$. fasciculatus forages for dung in the closed habitat of the same bioregion.

\subsection{Differences in Eye Size and Shape}

The relatively big eye $\left(1.60 \pm 0.57 \mathrm{~mm}^{2}\right)$ of $K$. nigroaeneus is completely divided into a dorsal $\left(0.59 \pm 0.22 \mathrm{~mm}^{2}\right)$ and a ventral part (Figure 2a), while the smaller eyes of G. unicolor $\left(0.21 \pm 0.03 \mathrm{~mm}^{2}\right)$ and $S$. fasciculatus $\left(0.15 \pm 0.03 \mathrm{~mm}^{2}\right)$ rather have a more oval-shaped dorsal eye (0.05 \pm 0.01 and $0.02 \pm 0.01 \mathrm{~mm}^{2}$, respectively) which connects to the ventral part of the eye $(\mathrm{N}=10)$ (Figure $2 \mathrm{~b}, \mathrm{c})$ (for detailed data see Supplementary Table S1).

\subsection{Orientation Performance under the Natural Sky Is Equal for All Species}

The outdoor orientation performance of the three species, as determined from the mean resultant vector length $(\mathrm{R})$ of 10 exit bearings per beetle from the centre of the circular arena (the closer to 1 , the better oriented the beetle) did not differ between the species 
(K. nigroaeneus: $\mathrm{R}=0.93 \pm 0.1$; G. unicolor: $\mathrm{R}=0.93 \pm 0.1$; . fasciculatus: $\mathrm{R}=0.88 \pm 0.1$, $p=0.15$, Kruskal-Wallis test, $\mathrm{N}=10$ ) (for detailed data see Supplementary Table S2). We also found that within a species, the first bearing chosen by each individual was not biased towards any particular heading (K. nigroaeneus: $p=0.06, Z=2.8$; G. unicolor: $p=0.54$, $Z=0.64 ;$ S. fasciculatus: $p=0.22, Z=1.53$, Rayleigh uniformity test, $N=10$ ). Although the evidence for this was weaker in K. nigroaeneus $(p=0.06)$, previous work on closely related Scarabaeini species $[22,30]$ suggests that this is most likely an effect of the small sample size. Taken together, this indicates that, under an open sky, our test species, from three different tribes, are able to travel along any given bearing with the same angular precision.

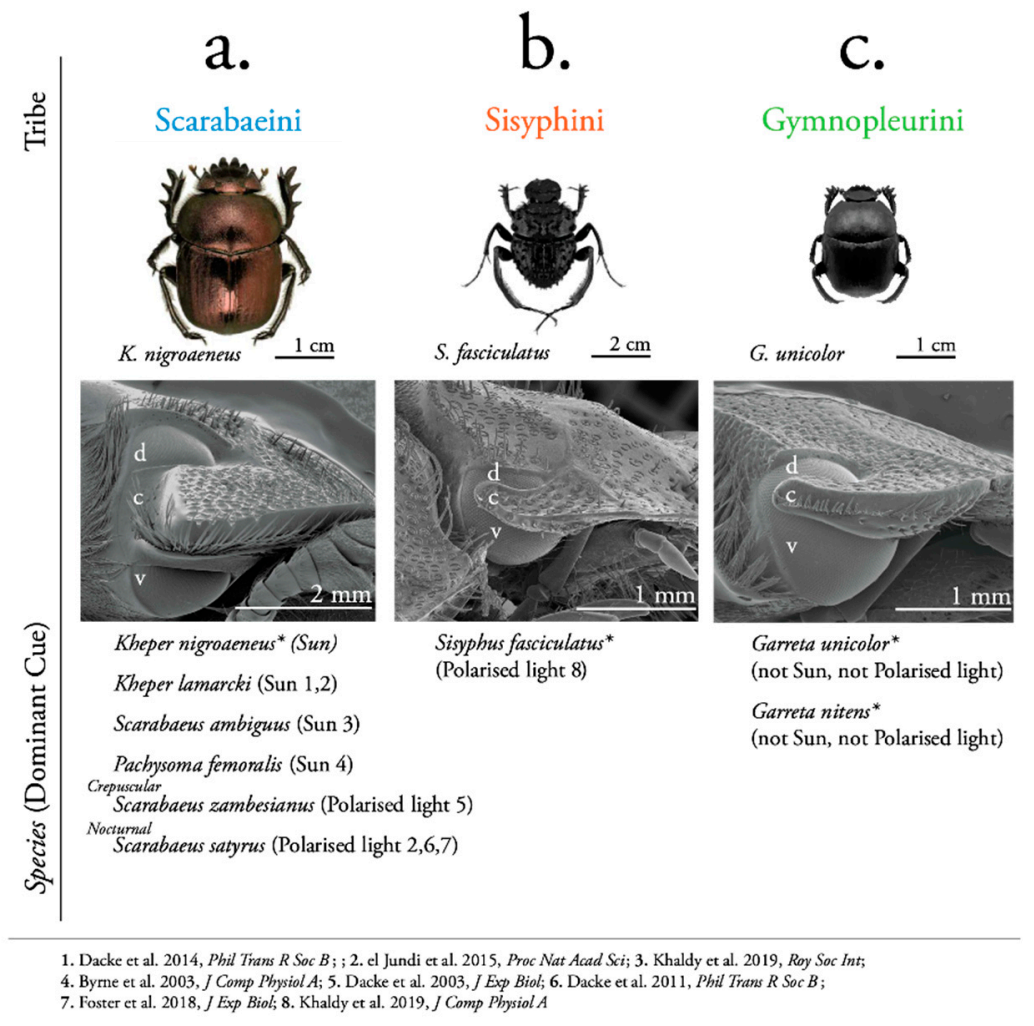

Figure 2. Habitus, eye design and dominant orientation cue in three tribes of ball-rolling dung beetles. Diurnal species within the tribe Scarabaeini (a) attribute greatest relative weight to directional information provided by the sun during straight-line orientation. In contrast, two nocturnal species from the same tribe, as well as the smaller, diurnal Sisyphus fasciculatus, from the tribe Sisyphini (b), rely predominantly on polarised skylight for directional information. The underlying weighting strategy for straight-line orientation within the tribe Gymnopleurini (c) differs from that previously mentioned, where neither directional information from the sun nor the polarisation pattern dominates the output from its compass network. As can also be noted from our test species, Sisyphini are generally much smaller than Gymnopleurini, which in turn are smaller than Scarabaeini. The relative eye sizes across the three tribes follow the same pattern, but they differ in shape. The canthus $(c)$ completely separates the roughly equal sized dorsal $(d)$ and ventral $(v)$ eyes of the Scarabaeini, while the dorsal portion of the eye of the Gymnopleurini and Sisyphini is only partially separated and much smaller than the ventral part. Species tested in this study are indicated by an asterisk $\left(^{*}\right)$.

\subsection{Ball-Rolling Dung Beetles Can Orient to a Single Green Light Spot}

Beetles presented with a green light spot (indoors) as an ersatz sun in the same azimuthal position between two consecutive exits from the centre of the arena (control), and showed no significant change in direction in any of the three species, (K. nigroaeneus: $\mu=28.37^{\circ} \pm 49.27^{\circ}, p<0.01, \mathrm{~V}=2.72$; G. unicolor: $\mu=333.7^{\circ} \pm 54.70^{\circ}, p<0.01, \mathrm{~V}=2.54$; S. fasciculatus: $\mu=5.13^{\circ} \pm 39.89^{\circ}, p<0.001, \mathrm{~V}=3.50$, mean \pm circular s.d., $\mathrm{v}$-test (with the expected mean of $0^{\circ}$ ), $\mathrm{N}=10$ ) (Figure $3 \mathrm{a}$, grey dotted vector). 


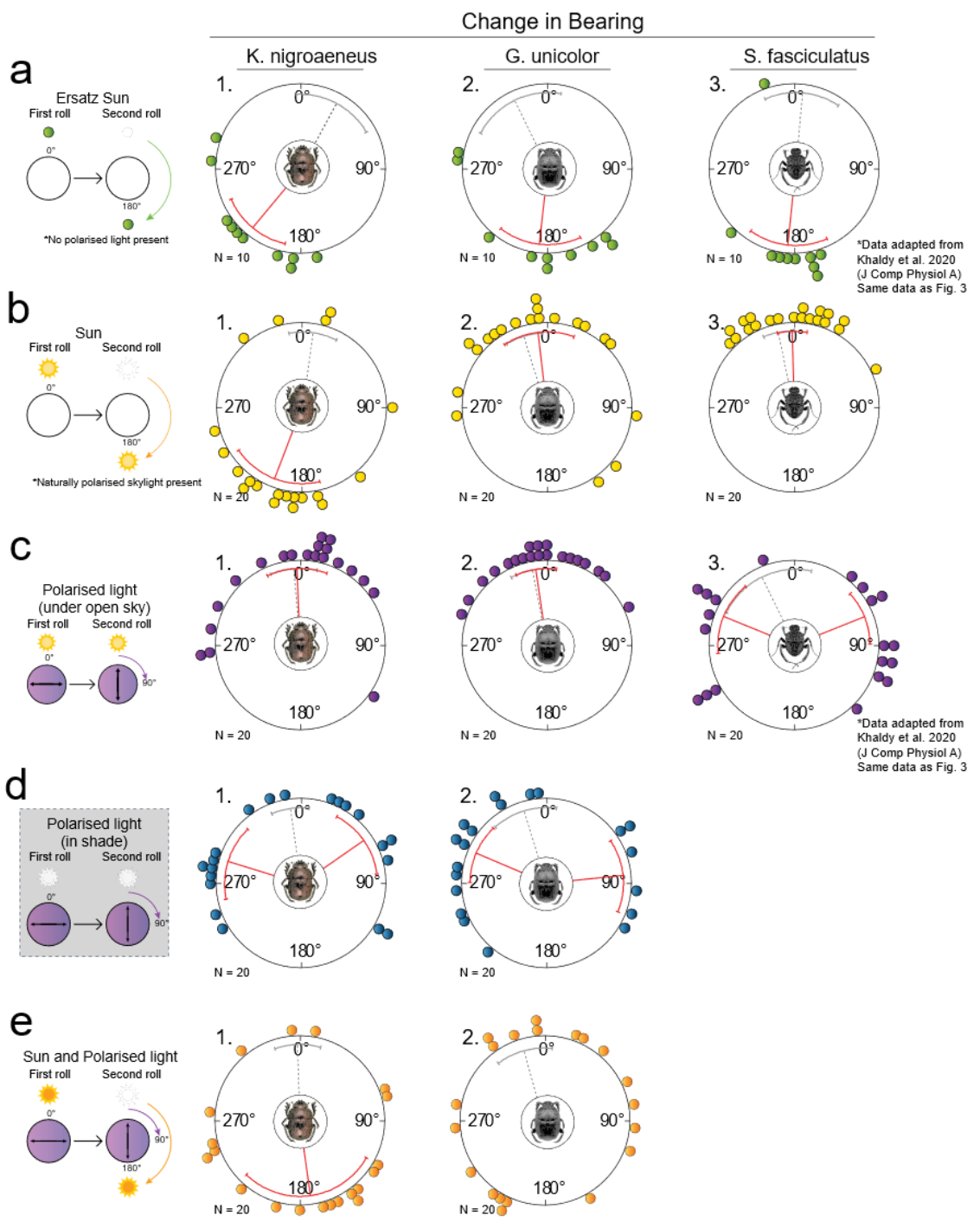

Figure 3. Response to directional change of compass cues. Three diurnal dung beetle species (from left to right; Kheper nigroaeneus, Garreta unicolor and Sisyphus fasciculatus) were allowed to roll balls out of a circular arena in a darkened room (a) or outdoors under the open sky (b), or with a polarisation filter placed above the arena with the sun visible (c,e) or with a polarisation filter placed above the arena with the sun shielded from view (d). Once the beetle had reached the periphery of the arena, it was removed from its dung ball and placed back in the centre alongside its ball. At this time, the apparent position of the ersatz sun ((a), green arrow) or the real sun $\left((\mathbf{b})\right.$, orange arrow) was switched by $180^{\circ}$, the apparent e-vector direction was turned by $90^{\circ}$ using a polarisation filter $\left((\mathbf{c}, \mathbf{d})\right.$, purple arrow) or the position of the sun was changed by $180^{\circ}$ while simultaneously turning the apparent e-vector direction by $90^{\circ}$ ((e), orange arrow: sun; purple arrow: polarisation filter). The beetle was then allowed to exit the arena a second time. The absolute angular difference between the first and the second exit angle represent the response to the treatment (test). (a): With the ersatz sun switched by $180^{\circ}$, all three species changed their bearings in accordance with this angular change (red vector, all graphs); (b): with the sun mirrored by $180^{\circ}$ outdoors, only K. nigroaeneus showed a significant change in bearings in response to this manipulation; (c): with the e-vector turned by $90^{\circ}$ under a clear sky, only S. fasciculatus responded significantly by a change in exit bearings approaching $90^{\circ}$; (d): with the sun shielded from view, a significant change in bearings could also be elicited in K. nigroaeneus and G. unicolor; (e): with the sun mirrored by $180^{\circ}$ and the polarisation pattern e-vector turned by $90^{\circ}, \mathrm{K}$. nigroaeneus changed its exit bearings in a similar fashion to when only the sun was mirrored by $180^{\circ}$ (see graph 1 in (b)), while the changes in exit bearings for G. unicolor were randomly distributed within the population (graph 2). Beetles were then allowed to roll a third time, with the manipulated cue(s) moved back to its/their initial position. The mean angular difference between the first and second exit (test), and the first and third exit (control), is represented by a red solid vector and a grey dotted vector, respectively, in each graph. Error bars represent one circular standard deviation. The data presented for S. fasciculatus in (a) and (c) (graph 3, respectively) were adapted from Khaldy et al., 2020 [26]. For detailed data see Supplementary Table S3. 
When the position of the ersatz sun was changed by $180^{\circ}$ between two exits from the centre of the arena (test), all species changed their headings accordingly (K. nigroaeneus: $\mu=219.59^{\circ} \pm 37.73^{\circ}, p<0.01, \mathrm{~V}=2.77 ;$ G. unicolor: $\mu=186.27^{\circ} \pm 49.40^{\circ}, p<0.001, \mathrm{~V}=3.47 ;$ S. fasciculatus: $\mu=185.9^{\circ} \pm 41.67^{\circ}, p<0.001, \mathrm{~V}=3.41$, v-test (with the expected mean of $180^{\circ}$ ), $\mathrm{N}=10$ ) (Figure 3a). These changes in headings showed that the species tested can steer with reference to a single point-light source and with no significant difference in performance between species $(p=0.139, \mathrm{~W}=6.95$, Mardia-Watson-Wheeler test, $\mathrm{N}=10$ ).

\subsection{The Role of the Sun in the Orientation System of Ball-Rolling Dung Beetles}

When allowed to exit the arena under the open sky, followed by an exit where the apparent solar position was mirrored by $180^{\circ}$ (test), K. nigroaeneus still showed a marked change in heading $\left(\mu=201.05^{\circ} \pm 69.46^{\circ}, p<0.01, \mathrm{~V}=2.83\right.$, v-test (with an expected mean of $180^{\circ}$ ), $\mathrm{N}=20$ ) (Figure $3 \mathrm{~b}$, graph 1 ). In contrast, the differences in headings travelled by G. unicolor and S. fasciculatus in response to this treatment clustered around $0^{\circ}(\mathrm{G}$. unicolor: $\mu=353.4^{\circ} \pm 59.31^{\circ}, p<0.001, \mathrm{~V}=3.68 ;$ S. fasciculatus: $\mu=358.37^{\circ} \pm 25.58^{\circ}, p<0.001$, $\mathrm{V}=5.72$, v-test (with an expected mean of $0^{\circ}$ ), $\mathrm{N}=20$ ) (Figure 3b, graph 2,3).

As for the control for the experimental treatment (including our handling of the beetles), the changes in bearing between two exits under an unmanipulated sky was also calculated (control); the average change of bearings was clustered around $0^{\circ}$ for all species (K. nigroaeneus: $\mu=8.01^{\circ} \pm 42.34^{\circ}, p<0.001, V=4.77$; G. unicolor: $\mu=342.76^{\circ} \pm 32.52^{\circ}$, $p<0.001, \mathrm{~V}=5.14 ;$ S. fasciculatus: $\mu=348.65^{\circ} \pm 26.71^{\circ}, p<0.001, \mathrm{~V}=5.57$, v-test (with an expected mean of $0^{\circ}$ ), $\mathrm{N}=20$ ) (Figure $3 \mathrm{~b}$, grey dotted vector). In addition, no significant difference in orientation performance was observed between the test and control conditions for G. unicolor and S. fasciculatus (G. unicolor: $p=0.61, W=0.98$; S. fasciculatus: $p=0.50$, $\mathrm{W}=1.4$, Mardia-Watson-Wheeler test, $\mathrm{N}=20$ ). Together, these results indicate that directional information from the sun is given a greater relative weight in the orientation system of K. nigroaeneus compared to that of G. unicolor and S. fasciculatus.

\subsection{The Role of Polarised Light in the Orientation System of Ball-Rolling Dung Beetles}

When a polarising filter was placed above the arena aligned to the dominant e-vector direction in the open sky, then followed by a $90^{\circ}$ rotation of the filter for the second exit (or vice versa), S. fasciculatus changed their heading by $82.75^{\circ} \pm 30.50^{\circ}(\mathrm{N}=20)$ (Figure $3 \mathrm{c}$, graph 3). In contrast, the change in headings recorded for K. nigroaeneus and G. unicolor clustered closer to $0^{\circ}\left(\mathrm{K}\right.$. nigroaeneus: $\mu=357.64^{\circ} \pm 51.71^{\circ}, p<0.001, \mathrm{~V}=4.22 ; \mathrm{G}$. unicolor: $\mu=351.83^{\circ} \pm 36.02^{\circ}, p<0.001, \mathrm{~V}=5.14, \mathrm{v}$-test (with an expected mean of $0^{\circ}$ ), $\mathrm{N}=20$ ) (Figure 3c, graph 1,2), indicating that these beetles did not respond to the $90^{\circ}$ rotation of the polariser. This suggests that directional information from the overhead pattern of polarised skylight is given a greater relative weight in the orientation system of $S$. fasciculatus compared to that of K. nigroaeneus and G. unicolor.

When exiting twice from under a polarising filter kept in the same orientation (control), no significant change in direction was observed for any of the three species (K. nigroaeneus: $\mu=355.16^{\circ} \pm 40.91^{\circ}, p<0.001, \mathrm{~V}=4.88$; G. unicolor: $\mu=349.11^{\circ} \pm 38.87^{\circ}, p<0.001$, $\mathrm{V}=4.93$; S. fasciculatus: $\mu=333.71^{\circ} \pm 73.49^{\circ}, p<0.01, \mathrm{~V}=4.84$, v-test (with an expected mean of $0^{\circ}$ ), $N=20$ ). In addition, no significant difference in orientation performance was observed when exiting twice under a unmanipulated polarising filter compared to exiting twice under an unmanipulated sky (K. nigroaeneus: $p=0.84, \mathrm{~W}=0.36$; $G$. unicolor: $p=0.93, \mathrm{~W}=0.15 ;$ S. fasciculatus: $p=0.99, \mathrm{~W}=0.015$, Mardia-Watson-Wheeler test, $\mathrm{N}=20$ ), demonstrating that the addition of the polarisation filter did not have an effect on orientation performance (Figure 3c, grey dotted vector).

To further investigate the role of polarised skylight on the orientation system of $K$. nigroaeneus and G. unicolor, the polarising filter was again placed above the arena, but now with the sun obstructed from view. The changes in headings recorded for the two species in response to a $90^{\circ}$ rotation of the filter now clustered around $67.36^{\circ} \pm 35.45^{\circ}$ for $\mathrm{K}$. $n i$ groaeneus, and around $72.49^{\circ} \pm 36.57^{\circ}$ for G. unicolor $(\mathrm{N}=20)$ (Figure 3d), demonstrating 
that when the sun is obstructed from view, directional information from the overhead polarised light pattern is now attributed a relatively greater weight in the orientation system of these two species.

\subsection{The Combined Role of Sun and Polarised Skylight in the Orientation System of Garreta Unicolor and $G$. nitens}

Given that G. unicolor did not turn despite a displacement of the sun or rotation of the pattern of polarised light under the open sky but did orient to an ersatz sun indoors and to a polarised light pattern in the shade, we then rotated the polariser by $90^{\circ}$ while simultaneously mirroring the sun by $180^{\circ}$ and shielding the real sun from the beetle's view (Figure 3e, graph 2). To our surprise, the angular changes in bearing recorded for G. unicolor in response to this manipulation were not different from a random distribution ( $p=0.70, Z=0.37$, Rayleigh uniformity test, $\mathrm{N}=20$ ) (Figure 3e, graph 2 ). It is important to note that the beetles still maintained a straight trajectory when rolling. As soon as the real sun was revealed and the polarising filter was turned back to its original position, the beetles resumed their initial direction of travel $\left(\mu=344.67^{\circ} \pm 49.03^{\circ}, p<0.001, \mathrm{~V}=4.23\right.$, $\mathrm{v}$-test (with an expected mean of $0^{\circ}$ ), $\mathrm{N}=20$ ).

To further evaluate this somewhat surprising observation, we repeated this experiment on K. nigroaeneus and the close relative G. nitens (due to their experimentally frailer nature, the tiny $S$. fasciculatus would not perform under this condition, but rather flew away from the setup at any given chance). While $K$. nigroaeneus altered its heading towards a $180^{\circ}$ turn $\left(\mu=171.92^{\circ} \pm 85.32^{\circ}, p=0.02, V=2.07\right.$, v-test (with an expected mean of $180^{\circ}$ ), $\mathrm{N}=20$ ) (Figure 3e, graph 1), the experimental outcome for $G$. nitens was similar to that of its congeneric: no change in bearing when the solar position was mirrored by $180^{\circ}$ $\left(\mu=358.37^{\circ} \pm 25.56^{\circ}\right)$ or in response to the $90^{\circ}$ turn of the e-vector $\left(\mu=4.78^{\circ} \pm 49.91^{\circ}\right)$, but a significant change in bearing when the two cues were rotated together $(p<0.001$, $W=18.28$, Mardia-Watson-Wheeler test, $\mathrm{N}=20$ ) (). Similar to our findings for $G$. unicolor, the change in bearing recorded for $G$. nitens in response to simultaneous manipulation, were randomly distributed within the population $(p=0.44, Z=0.83$, Rayleigh uniformity test, $\mathrm{N}=20$ ). The beetles returned to their initial direction of travel as soon as the cues were rotated back to their original positions $\left(\mu=8.57^{\circ} \pm 39.90^{\circ}, p<0.001, V=4.91\right.$, v-test (with an expected mean of $\left.0^{\circ}\right), \mathrm{N}=20$ ).

\section{Discussion}

In this study, we demonstrated how the orientation system of ball-rolling dung beetles, belonging to three different tribes that co-occur within the same savanna biome, attribute different relative weights to directional information during straight-line orientation.

\subsection{Diurnal Scarabaeini Attribute the Greatest Relative Weight to the Directional Information Provided by the Sun}

As with sandhoppers, monarch butterflies and birds [41-43], ball-rolling dung beetles can direct their straight-line movements according to directional input from a single source of light in an indoor setting (Figure $3 \mathrm{a}$ and $[21,24,27]$ ). Outdoors, however, the beetles are exposed to a range of celestial directional cues, including the sun, polarised skylight [44-46], as well as the gradients of intensity [47] and colour [48-50] that form across the natural sky. Therefore, if the apparent position of the real sun is changed by $180^{\circ}$ with the aid of a mirror and a shading board, the directional information from the sun is set in conflict with that of the rest of the sky. Nevertheless, Kheper nigroaeneus changed its roll bearing in accordance with such an experimental displacement of the sun (Figure 3b, graph 1). A comparable response to this manipulation has also been documented for three other members of the Scarabaeini; K. lamarcki [21,23], Scarabaeus ambiguus (Boheman) [30] and Pachysoma femoralis Kirby [24], suggesting that the orientation system of these species attributes the greatest relative weight to the directional information provided by the sun.

Consistent with this observation, K. nigroaeneus did not respond to a $90^{\circ}$ turn of an artificial, highly polarised pattern of polarised light, when presented from above in full view 
of the unmanipulated sun (Figure 3c, graph 1). However, as soon the sun was hidden from view, the beetles showed a clear $90^{\circ}$ turn in response to the rotated polariser (Figure $3 \mathrm{~d}$, graph 1). It appears that once the sun is absent, which also naturally happens when it is obscured by a passing cloud, the distribution of the relative weight between the directional cues that remained can shift in favour of the polarised light input (Figure $3 \mathrm{~d}$, graph 1 ). The same holds true also for the close relative, K. lamarcki [28], where a behavioural response to the directional input from the gradients of colour and intensity can be seen when presented in isolation $[28,29]$.

\subsection{Sisyphus fasciculatus Attributes Greatest Relative Weight to the Directional Information Provided by the Celestial Polarisation Pattern}

Neither Garreta unicolor nor S. fasciculatus changed their bearings according to the displacement of the sun (Figure 3b, graph 2,3), indicating that the relative weight attributed to this directional cue in their orientation system is somewhat lower. This supports the results of a recent study [26], where, in contrast to Kheper nigroaeneus, S. fasciculatus turns in accordance with the turn of the polariser under a natural sky. Together, these findings clearly demonstrate that the smaller $S$. fasciculatus attributes the greatest relative weight to the directional information provided by the (artificial) linear pattern of polarised light. This sky-wide celestial cue is also known to play a significant role in the orientation system of other insects (locusts [51], honeybees [52] and bull ants [32]), and in some cases, even plays a dominant role (nocturnal dung beetles [21,53,54], flies [55] and desert ants [56]).

\subsection{A Different Weighting of Directional Reference Cues in Garreta Species}

To our surprise, G. unicolor kept to its original direction of travel both in the presence of a mirrored sun (Figure 3b, graph 2), and under a turned polariser (Figure 3c, graph 2). Only when these two cues were rotated in combination did this species demonstrate a behavioural response, which was an angular change in bearing which appeared to be randomly distributed within the population (Figure 3e, graph 2). A similar response could be confirmed in its congeneric, G. nitens (), suggesting that this is a tribe-specific orientation strategy.

Due to experimental constraints, this combined manipulation of directional information from the sun and the over-head pattern of polarisation was achieved by a $180^{\circ}$ shift in the apparent position of the sun in combination with a $90^{\circ}$ rotation of the polarisation pattern. The outcome of these manipulations was that the position of the two cues were not only changed in relation to the unmanipulated gradients of intensity and colour that spans the sky, but also in relation to each other. This drastic and multi-angular change in directional input could potentially cause the beetles to simply re-set their roll bearings, effectively contributing to the random changes in bearings displayed by G. unicolor (Figure 3e). However, this conjecture can be refuted, as the beetles faithfully returned to their initial bearings as soon as the cues were returned to their initial positions (Figure 3e, grey dotted vector, graph 2 ). Additionally, when tested under the same multi-conflict paradigm, $K$. nigroaeneus showed a clear and directed response. Attributing the greatest relative weight to the sun, these beetles simply continued to follow the angular displacement of this cue also under this experimental condition (compare Figure $3 b, e$ ). One possibility is of course that in our experiments with G. unicolor, each beetle followed an individual strategy; some turned $180^{\circ}$ according to the sun, some $90^{\circ}$ according to the overhead polarisation and some followed the stable gradients of intensity and colour. This is, however, unlikely, as we would then have expected to see a different and much more varied response when these cues were manipulated on their own (see Figure $3 b, c$ ). The random spread of changes in bearings observed for the Garreta sp. rather points to a more even weighting of directional information where the combined directional information in this artificial cue conflict experiment, results in a weak directional signal. While the beetles were still able to exit from the centre of the arena along straight paths, small, individual differences in the weighting of cues could now be seen in large differences in angular change. It would have been interesting to evaluate this theory further by testing the same beetle repeatedly before 
rotating all cues back to their initial positions again, but this was unfortunately not within the scope of this study.

While our results do not reveal the precise nature of the orientation strategy of the Garreta species, we can still conclude that the heading direction networks of our three test species process the directional information provided by the sky somewhat differently; $K$. nigroaeneus preferentially steers according to the sun, S. fasciculatus with the pattern of polarised light, and G. unicolor (and G. nitens) does not attribute a greater relative weight to either of these cues.

\subsection{Compass Cue Integration and Its Relation to the Visual Ecology of Ball-Rolling Dung Beetles}

Given that a navigator can reliably perceive and analyse directional information provided by the sun and its pattern of polarised light, neither of these cues should be inherently more reliable for orientation than the other. We previously showed that ballrolling beetles that attribute the greatest weight to directional information provided by the sun, are equally well directed in its absence when an alternative cue is available [23,28]. This holds true also for ants [56], monarch butterflies [9] and fruit flies [55]. It is further important to note, that the three tribes of dung beetles tested in this study-each attributing a different relative weight to the sun and the celestial polarised light pattern-all orient with the same precision under a clear, open sky (Figure $2 b$, grey mean vector (control)). Taken together, this indicates that the directional information provided by the sun or polarised light in the photon-rich African sky can (i) support orientation with the same precision, and (ii) be processed with comparable accuracy by the visual system and heading direction network of the Scarabaeini beetles. This is most likely also the case for the Gymnopleurini (species G. unicolor and G. nitens), that do not seem to employ differential weighting to any of the celestial cues tested.

Even though our test species are active within the same bioregion, K. nigroaeneus and G. unicolor were found actively foraging in the open habitat (Figure 1a), while the smaller $S$. fasciculatus rather foraged for dung within the closed habitat (Figure 1b). In this habitat, with tall grass and a high density of trees, the sun will be frequently obstructed from view, while a wide-field cue, such as the celestial polarised light pattern, will remain visible through any overhead vegetation $[45,57,58]$. This is also the cue attributed the highest directional weight in the orientation system of S. fasciculatus [26]. While it would have been preferable to explore the orientation strategy of additional species within the tribe Sisyphini from a different visual habitat, this unfortunately proved impossible as the species available to us (Sisyphus manni [59] and Sisyphus seminulum [60]) are so small (pronotum width: 3-5 mm) and timid, that not even the most experienced beetle experimentalist could coerce them into performing in our experiments. Still, our limited results from this tribe again suggest that they afford the greatest weight to the most consistent source of celestial directional information in their cluttered habitat [7], a strategy also found in ants [18,19].

As day turns into night, the visual world changes drastically, most notably in the decrease in light intensity [61]. At this time of the day, visually driven orientation systems need to capture as much light as possible. One common way to meet this challenge is by an increase in eye size [62,63], but it is also interesting to note that some neurons within the heading direction network of the desert locust have a higher absolute sensitivity to polarised than to unpolarised light [64]. The larger eyes of the nocturnal, open habitat Scarabaeini beetles (Scarabaeus satyrus and S. zambesianus), possess a large dorsal rim area (DRA) (the polarisation sensitive region known to detect polarised light in insects [65-67]) and rely on directional information from the polarised skylight above that provided by the moon itself $[25,53,54]$. In contrast, the diurnal $K$. lamarcki, which is active in the same habitat, only possess a single dorsal row of polarisation-sensitive ommatidia (Dacke unpublished data). The orientation systems of beetles active under more challenging light conditions-in the dark or under vegetation canopies-thus seem well adapted to their respective visual ecologies.

It is interesting to note that differences in external eye morphology between the ball-rolling beetles are more pronounced between the three tribes, than within the tribes 
themselves [68] (Figure 2). As representatives of their respective tribes ([69-71]), S. fasciculatus and G. unicolor possess a more oval-shaped dorsal eye compared to that of $K$. nigroaeneus, where the dorsal eye of the medium-sized G. unicolor is proportionally smaller than that of K. nigroaeneus, while the small and spindly $S$. fasciculatus has the smallest dorsal eye of the three (Figure $2 b$ ). If we would assume that the small and narrow dorsal eyes of the smaller species also have a smaller visual field [72-76], the heading direction networks of the narrow-eyed Sisyphini and Gymnopleurini could possibly benefit from a sky-wide orientation signal, such as the celestial polarisation pattern, rather than using the position of a single light source. These inter-tribal differences might be an additional influence on how species within each tribe weight the sources of directional information they can reliably use.

In conclusion, despite exhibiting different body size, eye size and morphology, dung beetles nevertheless manage to solve the challenge of straight-line orientation by weighting visual cues that are particular to the habitat in which they are found. This system is however dynamic, allowing them to operate equally well even in the absence of the cue given the greatest relative weight by the particular species.

Supplementary Materials: The following are available online at https:/ /www.mdpi.com/article/10.3 390/insects12060526/s1, Table S1: Eye area and step size for K. nigroaeneus, G. unicolor and S. fasciculatus; Table S2: Exit angles $\left(0-359^{\circ}\right)$ of ten exit rolls of ten individuals of K. nigroaeneus, G. unicolor and S. fasciculatus, respectively, and the corresponding calculated mean vector length (R); Table S3: Absolute angular difference in exit bearing of each manipulation (test: first and second exit bearing; control: first and third exit bearing) for each individual beetle, in each paradigm; Supplementary Figure S1: Response to the directional change of compass cues in G. nitens. (https: / / doi.org/10.5281/zenodo.4891096, accessed on 1 June 2021).

Author Contributions: Conceptualization, L.K. and M.D.; Data Curation, L.K. and C.T.; Formal Analysis, L.K. and M.D.; Funding Acquisition, M.D.; Investigation, L.K., C.T., M.D., M.B.; Methodology, L.K., C.T. and M.D.; Project Administration, L.K., M.D. and M.B.; Resources, M.B. and M.D.; Supervision, M.D.; Validation, M.D.; Visualization, L.K., M.D.; Writing-Original Draft Preparation, L.K.; Writing-Review and Editing, L.K., C.T., M.B. and M.D. All authors have read and agreed to the published version of the manuscript.

Funding: Funding was provided by the Swedish Research Council (2014-04623, MD) and the European Research Council (817535-Ultimate-COMPASS, MD).

Institutional Review Board Statement: All experiments in this study were performed in accordance with the ethical standards required by the South African and Swedish guidelines for animal experiments.

Data Availability Statement: All data supporting reported results can be found in Supplementary Materials.

Acknowledgments: The authors wish to thank James Foster, Shahrzad Shaverdian, Elin Dirlik and Cody Manchester for assistance in the field. We also thank the team at Pullen farm, and Adventures with Elephants for allowing us to work on their reserve.

Conflicts of Interest: The authors declare no conflict of interest. The funders had no role in the design of the study; in the collection, analyses or interpretation of data; in the writing of the manuscript; or in the decision to publish the results.

\section{References}

1. Dacke, M.; Bell, A.T.A.; Foster, J.J.; Baird, E.J.; Strube-Bloss, M.F.; Byrne, M.J.; el Jundi, B. Multimodal cue integration in the dung beetle compass. Proc. Natl. Acad. Sci. USA 2019, 116, 14248-14253. [CrossRef]

2. Buehlmann, C.; Mangan, M.; Graham, P. Multimodal interactions in insect navigation. Anim. Cogn. 2020, $23,1129-1141$. [CrossRef]

3. Guerra, P.A.; Gegear, R.J.; Reppert, S.M. A magnetic compass aids monarch butterfly migration. Nat. Commun. 2014, 5, 4164. [CrossRef]

4. Frye, M.A.; Tarsitano, M.; Dickinson, M.H. Odor localization requires visual feedback during free flight in Drosophila melanogaster. J. Exp. Biol. 2003, 206, 843-855. [CrossRef] 
5. Ostwald, M.M.; Shaffer, Z.; Pratt, S.C.; Fewell, J.H. Multimodal cues facilitate nest recognition in carpenter bee aggregations. Anim. Behav. 2019, 155, 45-51. [CrossRef]

6. Dreyer, D.; Frost, B.; Mouritsen, H.; Günther, A.; Green, K.; Whitehouse, M.; Johnsen, S.; Heinze, S.; Warrant, E. The Earth's magnetic field and visual landmarks steer migratory flight behavior in the nocturnal Australian bogong moth. Curr. Biol. 2018, 28, 2160-2166. [CrossRef] [PubMed]

7. Cheng, K.; Shettleworth, S.J.; Huttenlocher, J.; Rieser, J.J. Bayesian integration of spatial information. Psychol. Bull. 2007, 133, 625-637. [CrossRef] [PubMed]

8. Perez, S.; Taylor, O.; Jander, R. A sun compass in monarch butterflies. Nature 1997, 387. [CrossRef]

9. Reppert, S.M.; Zhu, H.; White, R.H. Polarized light helps monarch butterflies navigate. Curr. Biol. 2004, 14, 155-158. [CrossRef]

10. Heinze, S.; Reppert, S.M. Sun compass integration of skylight cues in migratory monarch butterflies. Neuron 2011, 69, 345-358. [CrossRef]

11. Froy, O.; Gotter, A.L.; Casselman, A.L.; Reppert, S.M. Illuminating the circadian clock in monarch butterfly migration. Science 2003, 300, 1303-1305. [CrossRef] [PubMed]

12. Müller, M.; Wehner, R. Wind and sky as compass cues in desert ant navigation. Naturwissenschaften 2007, 94, 589-594. [CrossRef] [PubMed]

13. Wystrach, A.; Mangan, M.; Webb, B. Optimal cue integration in ants. Proc. R. Soc. B 2015, 282. [CrossRef] [PubMed]

14. Bruck, J.N.; Allen, N.A.; Brass, K.E.; Horn, B.A.; Campbell, P. Species differences in egocentric navigation: The effect of burrowing ecology on a spatial cognitive trait in mice. Anim. Behav. 2017, 127, 67-73. [CrossRef]

15. Odling-Smee, L.C.; Boughman, J.W.; Braithwaite, V.A. Sympatric species of three-spine stickleback differ in their performance in a spatial learning task. Behav. Ecol. Sociobiol. 2008, 62, 1935-1945. [CrossRef]

16. Kimchi, T.; Terkel, J. Spatial learning and memory in the blind mole-rat in comparison with the laboratory rat and Levant vole. Anim. Behav. 2001, 61, 171-180. [CrossRef]

17. Beugnon, G.; Lachaud, J.-P.; Chagné, P. Use of long-term stored vector information in the neotropical ant Gigantiops destructor. J. Insect. Behav. 2005, 18, 415-432. [CrossRef]

18. Cheng, K.; Middleton, E.J.T.; Wehner, R. Vector-based and landmark-guided navigation in desert ants of the same species inhabiting landmark-free and landmark-rich environments. J. Exp. Biol. 2012, 215, 3169-3174. [CrossRef]

19. Bühlmann, C.; Cheng, K.; Wehner, R. Vector-based and landmark-guided navigation in desert ants inhabiting landmark-free and landmark-rich environments. J. Exp. Biol. 2011, 214, 2845-2853. [CrossRef]

20. Schultheiss, P.; Stannard, T.; Pereira, S.; Reynolds, A.M.; Wehner, R.; Cheng, K. Similarities and differences in path integration and search in two species of desert ants inhabiting a visually rich and a visually barren habitat. Behav. Ecol. Sociobiol. 2016, 70, 1319-1329. [CrossRef]

21. El Jundi, B.; Warrant, E.J.; Byrne, M.J.; Khaldy, L.; Baird, E.; Smolka, J.; Dacke, M. Neural coding underlying the cue preference for celestial orientation. Proc. Natl. Acad. Sci. USA 2015, 112, 11395-11400. [CrossRef] [PubMed]

22. Baird, E.; Byrne, M.J.; Scholtz, C.H.; Warrant, E.J.; Dacke, M. Bearing selection in ball-rolling dung beetles: Is it constant? J. Comp . Physiol. A 2010, 196, 801-806. [CrossRef]

23. Dacke, M.; el Jundi, B.; Smolka, J.; Byrne, M.; Baird, E. The role of the sun in the celestial compass of dung beetles. Phil. Trans. R. Soc. B 2014, 369. [CrossRef]

24. Byrne, M.; Dacke, M.; Nordström, P.; Scholtz, C.; Warrant, E. Visual cues used by ball-rolling dung beetles for orientation. J. Comp . Physiol. A 2003, 189, 411-418. [CrossRef]

25. Dacke, M.; Byrne, M.J.; Baird, E.; Scholtz, C.H.; Warrant, E.J. How dim is dim? Precision of the celestial compass in moonlight and sunlight. Phil. Trans. R. Soc. B 2011, 366, 697-702. [CrossRef] [PubMed]

26. Khaldy, L.; Tocco, C.; Byrne, M.; Baird, E.; Dacke, M. Straight-line orientation in the woodland-living beetle Sisyphus fasciculatus. J. Comp. Physiol. A 2020, 206, 327-335. [CrossRef] [PubMed]

27. Smolka, J.; Baird, E.; el Jundi, B.; Reber, T.; Byrne, M.J.; Dacke, M. Night sky orientation with diurnal and nocturnal eyes: Dim-light adaptations are critical when the moon is out of sight. Anim. Behav. 2016, 111, 127-146. [CrossRef]

28. El Jundi, B.; Smolka, J.; Baird, E.; Byrne, M.J.; Dacke, M. Diurnal dung beetles use the intensity gradient and the polarization pattern of the sky for orientation. J. Exp. Biol. 2014, 217, 2422-2429. [CrossRef] [PubMed]

29. El Jundi, B.; Foster, J.J.; Byrne, M.J.; Baird, E.; Dacke, M. Spectral information as an orientation cue in dung beetles. Biol. Lett. 2015, 11. [CrossRef]

30. Khaldy, L.; Peleg, O.; Tocco, C.; Mahadevan, L.; Byrne, M.; Dacke, M. The effect of step size on straight-line orientation. J. R. Soc. Interface 2019, 16. [CrossRef]

31. Dacke, M.; Nordström, P.; Scholtz, C.; Warrant, E. A specialized dorsal rim area for polarized light detection in the compound eye of the scarab beetle Pachysoma Striatum. J. Comp. Physiol. A 2002, 188, 211-216. [CrossRef]

32. Freas, C.A.; Narendra, A.; Lemesle, C.; Cheng, K. Polarized light use in the nocturnal bull ant, Myrmecia midas. R. Soc. Open. Sci. 2017, 4. [CrossRef]

33. Collett, M. How navigational guidance systems are combined in a desert ant. Curr. Biol. 2012, 22, 927-932. [CrossRef] [PubMed]

34. Lebhardt, F.; Ronacher, B. Interactions of the polarization and the sun compass in path integration of desert ants. J. Comp. Physiol. A 2014, 200, 711-720. [CrossRef] [PubMed] 
35. Reid, S.F.; Narendra, A.; Hemmi, J.M.; Zeil, J. Polarised skylight and the landmark panorama provide night-active bull ants with compass information during route following. J. Exp. Biol. 2011, 214, 363-370. [CrossRef]

36. Legge, E.L.G.; Wystrach, A.; Spetch, M.L.; Cheng, K. Combining sky and earth: Desert ants (Melophorus bagoti) show weighted integration of celestial and terrestrial cues. J. Exp. Biol. 2014, 217, 4159-4166. [CrossRef]

37. Scholtz, C.; Ranwashe, F. University of Pretoria: Dung Beetles (Coleoptera: Scarabaeidae: Scarabaeinae). South African National Biodiversity Institute. Available online: https:/ / doi.org/10.15468/bapci6 (accessed on 16 April 2021).

38. Zuur, A.F.; Ieno, E.N.; Smith, G.M. Analysing Ecological Data; Springer: New York, NY, USA, 2007.

39. Bates, D.; Mächler, M.; Bolker, B.; Walker, S. Fitting linear mixed-effects models using lme4. J. Stat. Soft. 2015, 67, 1-48. [CrossRef]

40. Batschelet, E. Circular Statistics in Biology; Academic Press: London, UK, 1981; pp. 54-58.

41. Ugolini, A.; Scapini, F.; Pardi, L. Interaction between solar orientation and landscape visibility in Talitrus saltator (Crustacea: Amphipoda). Mar. Biol. 1986, 90, 449-460. [CrossRef]

42. Franzke, M.; Kraus, C.; Dreyer, D.; Pfeiffer, K.; Beetz, M.J.; Stöckl, A.L.; Foster, J.J.; Warrant, E.J.; el Jundi, B. Spatial orientation based on multiple visual cues in non-migratory monarch butterflies. J. Exp. Biol. 2020, 223. [CrossRef]

43. Kramer, G. Experiments on bird orientation. Ibis 1952, 94, 265-285. [CrossRef]

44. Horváth, G.; Barta, A.; Hegedüs, R. Polarization of the sky. In Polarized Light and Polarization Vision in Animal Sciences, 2nd ed.; Horváth, G., Ed.; Springer: Berlin/Heidelberg, Germany, 2014; pp. 367-406.

45. Pomozi, I.; Horváth, G.; Wehner, R. How the clear-sky angle of polarization pattern continues underneath clouds: Full-sky measurements and implications for animal orientation. J. Exp. Biol. 2001, 204, 2933-2942. [CrossRef]

46. Suhai, B.; Horváth, G. How well does the Rayleigh model describe the e-vector distribution of skylight in clear and cloudy conditions? A full sky polarimetric study. J. Opt. Soc. Am. A 2004, 21, 1669-1676. [CrossRef]

47. Warrant, E.; Johnsen, S.; Nilsson, D.-E. Light and visual environments. Sci. Direct 2020, 1, 4-30. [CrossRef]

48. Coemans, M.A.J.M.; Vos Hzn, J.J.; Nuboer, J.F.W. The relation between celestial colour gradients and the position of the sun with regard to the sun compass. Vis. Res. 1993, 34, 1461-1470. [CrossRef]

49. Lord, R. On the light from the sky, its polarization and colour. Lon. Edinb. Dubl. Phil. Mag. J. Sci. 1871, 41, 107-120. [CrossRef]

50. Warrant, E.; Johnsen, S. Vision and the light environment. Curr. Biol. 2013, 23, 990-994. [CrossRef] [PubMed]

51. Zittrell, F.; Pfeiffer, K.; Homberg, U. Matched-filter coding of sky polarization results in an internal sun compass in the brain of the desert locust. Proc. Natl. Acad. Sci. USA 2020, 117, 25810-25817. [CrossRef] [PubMed]

52. Wehner, R.; Strasser, S. The POL area of the honeybee's eye- behavioural evidence. Physiol. Entomol. 1985, 10, 337-349. [CrossRef]

53. Foster, J.J.; Kirwan, J.D.; el Jundi, B.; Smolka, J.; Khaldy, L.; Baird, E.; Byrne, M.; Nilsson, D.-E.; Johnsen, S.; Dacke, M. Orienting to polarized light at night-Matching lunar skylight to performance in a nocturnal beetle. J. Exp. Biol. 2018, 222. [CrossRef]

54. Dacke, M.; Nordström, P.; Scholtz, C.H. Twilight orientation to polarised light in the crepuscular dung beetle Scarabaeus zambesianus. J. Exp. Biol. 2003, 206, 1535-1543. [CrossRef]

55. Weir, P.T.; Dickinson, M.H. Flying drosophila orient to sky polarization. Curr. Biol. 2012, 22, 21-27. [CrossRef] [PubMed]

56. Wehner, R.; Müller, M. The significance of direct sunlight and polarized skylight in the ant's celestial system of navigation. Proc. Natl. Acad. Sci. USA 2006, 103, 12575-12579. [CrossRef] [PubMed]

57. Hegedüs, R.; Barta, A.; Bernath, B.; Meyer-Rochow, V.B.; Horváth, G. Imaging polarimetry of forest canopies- how the azimuth direction of the sun, occluded by vegetation, can be assessed from the polarization pattern of the sunlit foliage. Appl. Opt. 2007, 46, 6019-6032. [CrossRef] [PubMed]

58. Shashar, N.; Cronin, T.; Wolff, L.; Condon, M. The polarization of light in a tropical rain forest. Biotropica 1988, 30, 275-285. Available online: https:/ / www.jstor.org/stable/2389169 (accessed on 17 July 2018). [CrossRef]

59. Montreuil, O. The species of Sisyphus Latreille, 1807 (Coleoptera, Scarabaeidae, Sisyphini) with tuffs of setae on elytra: First cases of brachypterism for this genus. Ann. Soc. Entomol. Fr. 2015, 51, 281-293. [CrossRef]

60. Paschalidis, K.M. The Genus Sisyphus Latr. (Coleoptera: Scarabaeidae). Master's Thesis, Rhodes University, Grahamstown, South Africa, December 1974.

61. Lythgoe, J.N. The Ecology of Vision; Clarendon Press: Oxford, UK, 1979; pp. 1-16.

62. Greiner, B.; Ribi, W.; Warrant, E. Retinal and optical adaptations for nocturnal vision in the halictid bee Megalopta genalis. Cell Tissue Res. 2004, 316, 377-390. [CrossRef] [PubMed]

63. Yack, J.E.; Johnson, S.E.; Brown, S.G.; Warrant, E.J. The eyes of Macrosoma Sp. (Lepidoptera: Hedyloidea): A nocturnal butterfly with superposition optics. Arthropod Struct. Dev. 2007, 36, 11-22. [CrossRef]

64. Kinoshita, M.; Pfeiffer, K.; Homberg, U. Spectral properties of identified polarized-light sensitive interneurons in the brain of the desert locust Schistocerca gregaria. J. Exp. Biol. 2007, 210, 1350-1361. [CrossRef]

65. Aepli, F.; Labhart, T.; Meyer, E.P. Structural specializations of the cornea and retina at the dorsal rim of the compound eye in hymenopteran insects. Cell Tissue Res. 1985, 239, 19-24. [CrossRef]

66. Labhart, T.; Meyer, E.P. Detectors for polarized skylight in insects: A survey of ommatidial specializations in the dorsal rim area of the compound eye. Microsc. Res. Tech. 1999, 47, 368-379. [CrossRef]

67. Labhart, T.; Meyer, E.P.; Schenker, L. Specialized ommatidia for polarization vision in the compound eye of cockchafers, Melolontha melolontha (Coleoptera, Scarabaeidae). Cell Tissue Res. 1992, 268, 419-429. [CrossRef]

68. Tocco, C.; Dacke, M.; Byrne, M. Eye and wing structure closely reflects the visual ecology of dung beetles. J. Comp. Physiol. A 2019, 205, 211-221. [CrossRef] 
69. Forgie, S.A.; Philips, T.K.; Scholtz, C.H. Evolution of the Scarabaeini (Scarabaeidae: Scarabaeinae). Syst. Entomol. 2005, 30, 60-96. [CrossRef]

70. Daniel, G.M.; Davis, A.L.V.; Sole, C.L.; Scholtz, C.H. Taxonomic review of the tribe Sisyphini sensu stricto (Coleoptera: Scarabaeidae: Scarabaeinae) in southern Africa, including new species descriptions. Insect. Syst. Evol. 2018, 51, 1-61. [CrossRef]

71. Hanski, I.; Cambefort, Y. Dung Beetle Ecology; Hanski, I., Cambefort, Y., Eds.; Princeton University Press: Oxford, UK, 1991; pp. 51-69.

72. Taylor, G.J.; Tichit, P.; Schmidt, M.D.; Bodey, A.J.; Rau, C.; Baird, E. Bumblebee visual allometry results in locally improved resolution and globally improved sensitivity. Elife 2019, 8. [CrossRef] [PubMed]

73. Land, M.; Nilsson, D.-E. What makes a good eye. In Animals Eyes, 2nd ed.; Oxford University Press: Oxford, UK, $2012 ;$ pp. 46-70.

74. Cronin, T.W.; Johnsen, S.; Marshall, J.N.; Warrant, E.J. Visual Ecology; Princeton University Press: Woodstock, UK; Oxfordshire, UK, 2014; pp. 66-116.

75. Rutowski, R.L.; Gislén, L.; Warrant, E.J. Visual acuity and sensitivity increase allometrically with body size in butterflies. Arthropod. Struct. Dev. 2009, 38, 91-100. [CrossRef]

76. Land, M. Visual Acuity in Insects. Annu. Rev. Ento. 1997, 42, 147-177. [CrossRef] [PubMed] 